\title{
AS POLÍTICAS PÚBLICAS DE LAZER E ESPORTE NO MUNICÍPIO DE ARUANÃ - GO'
}

\author{
Oromar Augusto dos Santos Nascimento \\ Universidade de Brasília, Distrito Federal, Brasília, Brasil \\ Ari Lazzarotti Filho \\ Universidade Federal de Goiás, Goiás, Goiânia, Brasil \\ Humberto Luis de Deus Inácio \\ Universidade Federal de Goiás, Goiás, Goiânia, Brasil
}

\begin{abstract}
Resumo
Esta pesquisa teve como objetivo investigar as políticas públicas de lazer e esporte no município de Aruanã - GO, destinadas aos seus moradores. Os instrumentos para a coleta de dados foram um roteiro de entrevista semiestruturada (adaptado de INÁCIO, 2007) com representantes da Gestão Municipal, a observação sistematizada e o registro de imagens dos espaços e equipamentos de lazer e esporte. Os resultados apontaram o esporte como conteúdo predominante do lazer presente nas políticas públicas, bem como o futebol como modalidade hegemônica, e que as ações voltadas aos moradores são reduzidas se comparadas às ações voltadas aos turistas. Concluímos que o lazer do cidadão encontra-se em condição de desvantagem em relação às políticas públicas voltadas para a demanda turística.
\end{abstract}

Palavras-chave: Políticas públicas; Lazer; Esporte; Aruanã

\section{Introdução}

Aruanã é uma cidade que pertence ao Estado de Goiás (Figura 1), localizada no noroeste goiano, fronteira com o Estado do Mato Grosso. Segundo o Instituto Brasileiro de Geografia e Estatística (IBGE), a cidade possui uma área de $3.050 .306 \mathrm{Km}^{2}$, uma população estimada em 2014 de 8.542 habitantes. Está localizada a $315 \mathrm{~km}$ de Goiânia, a capital do Estado de Goiás (via GO-070 e GO-164)².

O turismo gerado pelos atrativos naturais (rio Araguaia e rio Vermelho) é uma fonte significativa de emprego e renda da cidade; contudo este turismo é sazonal, concentrado principalmente no mês de julho. Ângela e Carvalho (2005) calcularam o valor recreativo do

\footnotetext{
${ }^{1}$ Esta pesquisa contou com financiamento da Fundação de Amparo à Pesquisa do Estado de Goiás (FAPEG).

2 Informações foram por nós mensuradas a partir dos dados do Google Maps®. Link para acesso: https://www.google.com.br/maps/dir/Goi\%C3\%A2nia,+GO/Aruan\%C3\%A3,+GO/@ -15.781682,-$\underline{50.163574,8 \mathrm{z} / \text { data }=! 4 \mathrm{~m} 13 ! 4 \mathrm{~m} 12 ! 1 \mathrm{~m} 5 ! 1 \mathrm{~m} 1 ! 1 \mathrm{~s} 0 \mathrm{x} 935 \mathrm{ef0ede} 1248 \mathrm{cf} 7: 0 x b a e d f f b f d 0 \mathrm{c} 11 \mathrm{fd} 1 ! 2 \mathrm{~m} 2 ! 1 \mathrm{~d}-}$ 49.2647885!2d-16.6868824!1m5!1m1!1s0x9368dc18fafcf5c5:0xedf4aef8e43933e7!2m2!1d-51.0753555!2d$\underline{14.9169655 ? \mathrm{hl}=\mathrm{pt}-\mathrm{BR} .}$
} 
rio Araguaia no ano de 2005, e chegaram ao valor de 17 bilhões de reais por ano, o que segundo as autoras, representa um valor subestimado, pois se embasaram num quantitativo mínimo de 40 mil turistas por ano.

Esse movimento turístico tem uma importância social, cultural e econômica distinta no estado de Goiás. Isto pode ser observado no período de férias escolares de julho, o qual corresponde a 30 dias $^{3}$, e é maior que em vários estados onde este período se configura apenas como recesso, geralmente igual ou inferior a 15 dias.

Figura 1 - Localização do Município de Aruanã em relação ao Estado de Goiás e ao Brasil

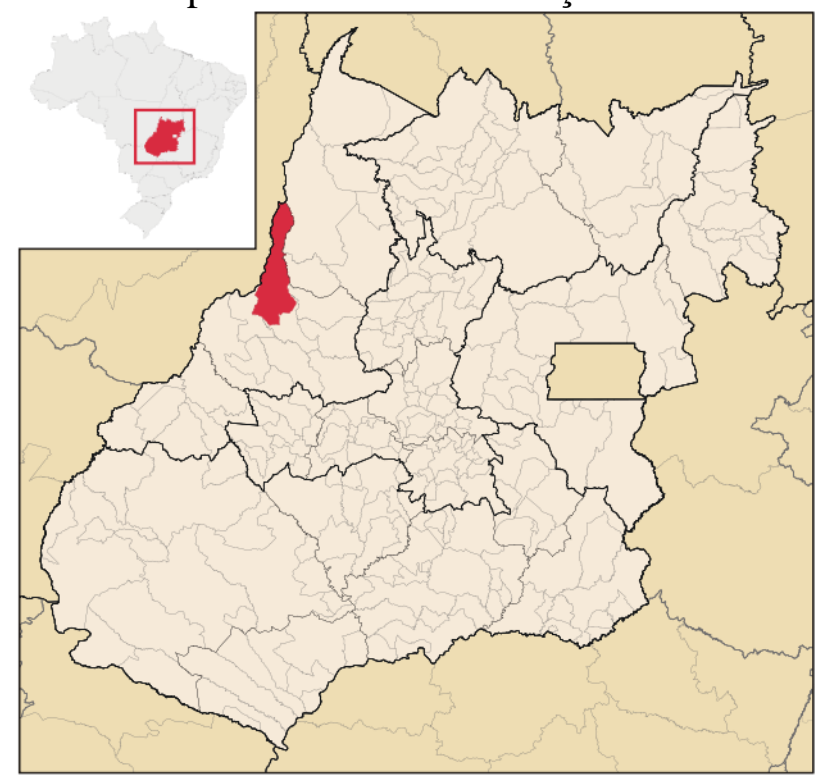

Fonte: Blog Municípios Goianos, (2014)

Nascimento e Inácio (2014) apontam que os acampamentos de férias no rio Araguaia, às margens de Aruanã, apresentam formas de organização que vão desde a instalação de ranchos e construções temporárias (de folhas e palha), até barracas com fogão, churrasqueira e geladeira. Destacam ainda acampamentos organizados por associações - como sindicatos da educação e de bancários, com atividades conduzidas por animadores socioculturais, diferentemente dos acampamentos familiares. Os autores perceberam um distanciamento dos gestores no que diz respeito às ações voltadas para práticas corporais direcionadas ao turista. Estes ocupam seu tempo disponível com outros interesses, mais próximos do descanso.

Dai, originou-se a intenção de investigar como a Gestão Municipal trata os cidadãos, buscando identificar políticas públicas de lazer, esporte e outras práticas para a população, já que em relação aos turistas estes dados pareciam estar mais claros.

Pesquisas sobre políticas públicas de esporte/lazer no Brasil têm tido cidades de portes médio e grande como objeto; nestas, o aporte de recursos financeiros possibilita ações mais frequentes e mesmo permanentes de esporte e lazer para suas populações - ressaltando-se que

\footnotetext{
${ }^{3}$ Dados obtidos através da comparação dos calendários escolares dos estados citados. Mais informações em: http://portal.seduc.go.gov.br/Arquivos/Calendario\%20Escolar\%202015.pdf
} 
há críticas a tais ações, em especial, pela hegemonia do esporte como conteúdo, pelo planejamento de cima para baixo, e pelo afunilamento dos recursos para equipes representativas da cidade em jogos de vários níveis (FREIRE; ROCHA JUNIOR, 2015); são raras as investigações em municípios menores.

Contudo, novas dinâmicas - tais como a formação em Educação Física no formato 'à distância', possibilitam que municípios menos abastados sejam estudados. Como se vê em Carneiro, Moraes e Soares (2014), numa investigação sobre espaços e equipamentos de esporte e lazer em Uruaçu - GO, onde apontaram a priorização do futebol pela Gestão Municipal, em detrimento de outras práticas, o que restringe o acesso da população ao esporte e lazer. ${ }^{4}$

No caso da cidade aqui pesquisada, a mesma se diferencia das demais por ser uma cidade pequena, mas com enorme aporte turístico sazonal, o que gera uma dinâmica distinta do poder municipal para os turistas e para a população local.

\section{Políticas públicas de esporte e lazer}

O Estado deve garantir ao cidadão o acesso a seus direitos pela formulação de políticas públicas. Segundo Silva et al (2011), as relações existentes no espaço público são mediadas pela política. Os autores compreendem o espaço público como qualquer espaço onde há acesso da população; inclusive espaços privados, como casas e estabelecimentos comerciais, são influenciados direta e indiretamente pela política. Nela encontram-se as relações de força, ou seja, as disputas de poder ocorrem a todo o momento.

Nenhuma decisão política é tomada por acaso, sem interesses e direcionamentos, pois as relações de poder entre os diversos agentes sociais e sua mediação nas múltiplas esferas no espaço público são condensadas nas políticas públicas.

Assim, podemos conceituar política pública como toda atividade política que tem como objeto específico assegurar, mediante a intervenção do Estado, o funcionamento harmonioso da sociedade, suplantando conflitos e garantindo a manutenção do sistema vigente [...] pensadas para atingir todas as camadas sociais. (AMARAL, 2004, p. 183).

Portanto as políticas públicas são estratégias e ações que o Estado tem de manter o funcionamento da sociedade, mediado pelas relações de poder existentes no cenário social, as quais interferem diretamente nas decisões tomadas pelos legisladores.

Starepravo (2011, p.34) indica que "A política pública muitas vezes é apenas a parte mais visível de todo um processo desenvolvido num espaço social específico, que comporta disputas, relações, alianças, decisões estratégicas ou não planejadas".

\footnotetext{
${ }^{4}$ Alguns estudos deste tipo foram realizados em TCCs do curso de Educação Física à distância da Universidade Federal de Goiás; possíveis pela presença de alunos de pequenas cidades do interior goiano. As conclusões de tais estudos indicam os mesmos resultados apontados por Carneiro, Moraes e Soares (2014), permitindo-nos generalizar a ideia de que cidades de pequeno porte priorizam o futebol em detrimento de inúmeras outras possibilidades.
} 
As ações deveriam indicar o acesso da população aos mais diversos tipos de conteúdos de lazer/esporte, evitando um modelo de transposição do alto rendimento esportivo para o lazer do cidadão. Desta forma, o espaço público de lazer pode conter as manifestações esportivas, mas ser democrático e oferecer alternativas que atendam aos mais diversos interesses, resultado das inúmeras dimensões humanas (RECHIA, 2005).

A garantia da diversidade de manifestações é questionada por Mascarenhas (2003), referindo-se ao processo de desapropriação da cultura local pela globalização. O autor utiliza o termo "Pedaço Sitiado", que se refere ao local/lugar onde coexistem diversas relações sociais, entre família, vizinhos, conhecidos, extrapolando os limites da casa, da propriedade privada, ocupando calçadas, espaços comunitários e pátios públicos. Ele se encontra sitiado por determinações da indústria cultural ${ }^{5}$, que ganha destaque com o avanço da globalização sobre os espaços do cotidiano (MASCARENHAS, 2003).

Com isto, podemos afirmar que as políticas públicas também estão sitiadas, pois são alvos de constantes investidas do mercado, deixando de lado as necessidades da população; aspectos da cultura local são mercadorizados e tem seu valor representado pelo potencial de consumo que pode gerar.

\section{Lazer e Esporte}

Entendemos o lazer como um elemento típico das sociedades modernas/contemporâneas, e que pode ter em seu cerne, bases para a construção de uma sociedade mais democrática.

Concordamos com a relação lazer-cidadania desenvolvida por Mascarenhas (2004), que compreende o lazer numa lógica neoliberal, com a redução do Estado Social, em que mudanças no cenário econômico acarretam mudanças nos direitos sociais como um todo, entre eles, no lazer, aproximando-o de sua mercadorização. Como alternativa a este processo, o autor apresenta o conceito de 'lazerania', o qual

[...] ao mesmo tempo em que procura expressar a possibilidade de apropriação do lazer como um tempo e espaço para a prática da liberdade, isto é, para o exercício da cidadania, busca traduzir a qualidade social de uma sociedade cujo direito ao lazer pode ter seu reconhecimento alicerçado sobre princípios como planificação, participação, autonomia, organização, justiça e democracia, deixando de ser monopólio ou instrumento daqueles que concentram poder econômico. (MASCARENHAS, 2004, p.74-75).

Estas ideias nos mostram que o lazer pode oferecer uma alternativa de liberdade das amarras do trabalho alienante, e não apenas como um escape da realidade, uma ferramenta de obtenção de satisfação pessoal por meio de atividades recreativas. O lazer pode ser um tempo de ressignificação de valores humanos, conforme aponta Inácio (1997):

(O lazer) elemento de oposição ao trabalho alienante limitador das possibilidades humanas, que deve ser transformado, como quer Pacheco, em

\footnotetext{
${ }^{5}$ A indústria cultural apresentada por Mascarenhas (2003) segue as ideias de Adorno e Horkheimer (1947).
} 
"um espaço de criação e recriação de identidades individuais e coletivas" (Pacheco (sic), 1992, p.252), com potencialidades no sentido de fazer emergir novos valores (ou valores já esquecidos) de cooperação e solidariedade, indispensáveis para um convívio harmonioso e justo entre os homens. (INÁCIO, 1997, p. 24).

Portanto, encontramos no lazer a possibilidade de um exercício da cidadania construído coletivamente. Quer dizer que as opções de lazer não devem ser verticalizadas e monopolizadas, mas representar um direito da população; assim, os espaços e equipamentos de lazer refletirão as vontades e necessidades das pessoas. Os conteúdos do lazer deveriam seguir esta mesma dinâmica. Neste sentido, o esporte - uma das possíveis manifestações de lazer assume papel significativo.

Bracht (2005) afirma que o esporte moderno tem origem por volta do século XVIII, e está relacionado à esportivização de elementos da cultura corporal europeia, e foi sendo disseminado pelo mundo por volta do final do século XIX. Fruto desta dinâmica, o esporte moderno é entendido como um fenômeno extremamente expressivo, com abrangência mundial, que acaba por incorporar práticas corporais de outras culturas além da europeia. Para o autor, em seu desenvolvimento no interior desta cultura, "[...] o esporte assumiu suas características básicas, que podem ser sumariamente resumidas em: competição, rendimento físico-técnico, recorde, racionalização e cientifização do treinamento." (BRACHT, 2005, p.14).

Stigger (2002) por sua vez, aponta a relevância social do esporte, tema de uma série de estudos sociológicos, os quais procuram compreender o fenômeno esportivo e seus significados. Este autor analisa o esporte desde um olhar sociocultural, construído "[...] em referências de diversas áreas como: a sociologia, a antropologia, a história e a filosofia" (STIGGER, 2002, p. 14). A partir de tal olhar, o autor pondera que

Ao reconhecer o esporte como um fenômeno cultural difundido globalmente, que traz consigo um universo de significações hegemonicamente colocadas, a intenção é compreendê-lo na sua expressão particular, vendo-o como uma prática social inserida no âmbito do lazer e como elemento constitutivo dos estilos de vida. Prática esta que, com características distintivas expressas nas diferentes formas de apropriação cultural do cotidiano dos atores sociais, vincula-se a uma realidade mais ampla da sociedade na qual está situada, numa relação de integração e de conflito. (STIGGER, 2002, p.75).

Este autor se mostra aberto à discussão do esporte como fenômeno cultural, que é determinado pela realidade social, mas que, dialeticamente, também determina o grande cenário ao se inserir nas práticas e espaços cotidianos de lazer das pessoas. Ele não se prende somente ao determinismo social do esporte, mas busca nele formas de criação de estilos de vida.

Percebemos que lazer e esporte se aproximam como fenômenos emergentes a partir do florescimento da sociedade industrial. Eles se popularizaram no decorrer do século XX, atraindo o interesse de diversos agentes sociais, como o Estado, o qual cria (ou não) mecanismos de acesso ao lazer e ao esporte por meio das políticas públicas. 


\section{Problema}

Os argumentos e ideias acima apresentados fomentam algumas reflexões e indagações acerca da realidade do nosso objeto de estudo, servindo de alicerce para nossa investigação, indicando possibilidades de análise dos dados da realidade. Desta maneira, nos deparamos com o seguinte problema de pesquisa: em Aruanã, uma cidade que recebe uma grande demanda turística anualmente - sua maior fonte de renda, como se apresentam as políticas públicas de lazer e esporte voltadas para o cidadão aruanense?

\section{Objetivo}

Traçamos como objetivo Investigar as políticas públicas de lazer e esporte na cidade de Aruanã - GO para seus habitantes, no que tange a seus espaços, equipamentos e a relação com a temporada de praia do rio Araguaia.

\section{Metodologia}

Esta pesquisa se aproxima de uma abordagem qualitativa, a qual, segundo Chizotti (1998, p.79),

[...] parte do fundamento de que há uma relação dinâmica entre o mundo real e o sujeito, uma interdependência viva entre o sujeito e o objeto, um vínculo indissociável entre o mundo objetivo e a subjetividade do sujeito [...]. O objeto não é um dado inerte e neutro; está possuído de significados e relações que sujeitos concretos criam em suas ações.

Na coleta de dados foram utilizadas: a) entrevista semiestruturada com representantes da Gestão Municipal, que foi gravada para posterior transcrição/análise; b) observação sistematizada dos espaços e equipamentos da cidade e, c) registro de imagens dos locais, folders, panfletos e cartazes sobre os eventos da cidade. ${ }^{6}$ Os dados foram coletados nos meses de julho de 2013 e 2014. O roteiro da entrevista foi adaptado de Inácio (2007), com a adição de tópicos de outras pesquisas desenvolvidas pelo GEPELC (Grupo de Estudos e Pesquisas em Esporte, Lazer e Comunicação).

Negrine (1999) afirma que a entrevista é semiestruturada quando permite ao entrevistado dissertar sobre os temas do roteiro, bem como abordar outros aspectos relevantes que não se encontram nele. Por sua vez, sobre a observação sistemática, Marconi e Lakatos (1991, p.193) afirmam que "realiza-se em condições controladas, para responder a propósitos preestabelecidos. Todavia, as normas não devem ser padronizadas nem rígidas demais, pois tanto as situações quanto os objetos e objetivos da investigação podem ser muito diferentes."

Os dados coletados nas entrevistas foram transcritos nas dependências da Faculdade de Educação Física e Dança da UFG, com o auxílio do software Olympus DSS Player

\footnotetext{
${ }^{6}$ Em nossa investigação não tivemos contato com documentos referentes à legislação da cidade.
} 
Standard Transcription Module ${ }^{\circledR}$, bem como com o equipamento Olympus Foot Switch RS 28 for $P C$, para maior agilidade. ${ }^{7}$

A análise do conjunto de dados baseou-se na triangulação de dados. Azevedo et al (2013) afirmam que a triangulação pode combinar diversos métodos e fontes de coleta de dados contribuindo para que o olhar sobre o objeto estudado aconteça sob diversas perspectivas, enriquecendo sua compreensão.

A organização dos dados seguiu a orientação de Gomes et al (2005), havendo em um primeiro momento a avaliação do material disponível, identificando as características e qualidades dos mesmos, em seguida a elaboração de estruturas de análises, que é a classificação dos dados em categorias que facilitem sua compreensão.

\section{Resultados e discussão}

Observamos que, em Aruanã, as políticas públicas de lazer estão intimamente vinculadas às políticas de esporte. Amostras desse fato são os espaços e equipamentos de lazer da cidade. A partir dos dados encontrados no site ${ }^{8}$ da prefeitura, que listava toda a infraestrutura da cidade, e de algumas falas dos gestores, construímos o Quadro 01, no qual se veem os espaços e equipamentos de lazer e esporte da cidade, classificados de acordo com Stucchi (1997).

Quadro 01 - Espaços e equipamentos de lazer da cidade de Aruanã informados pelo site da prefeitura e fala dos gestores.

\begin{tabular}{|l|l|l|c|c|}
\hline Local e caracterização. & $\begin{array}{l}\text { Equipamento } \\
\text { Específico } \\
\text { Especializado }\end{array}$ & $\begin{array}{l}\text { Equipamento } \\
\text { Polivalente }\end{array}$ & $\begin{array}{l}\text { Equipamento } \\
\text { Turístico }\end{array}$ & $\begin{array}{l}\text { Equipamento } \\
\text { Não } \\
\text { específico }\end{array}$ \\
\hline $\begin{array}{l}66 \mathrm{Km} \mathrm{(aproximadamente)} \mathrm{de} \\
\text { extensão de praias durante a } \\
\text { temporada de maio a setembro (mais } \\
\text { de 50 acampamentos) }\end{array}$ & & & $\mathrm{X}$ \\
\hline Arena para realização de rodeios & $\mathrm{X}$ & & & \\
\hline $\begin{array}{l}\text { Biblioteca comunitária Municipal - } \\
\text { Acervo de livros, revistas e outros } \\
\text { materiais, e rede de computadores } \\
\text { conectados com a internet. }\end{array}$ & $\mathrm{X}$ & & & \\
\hline Centro de convivência do idoso & & $\mathrm{X}$ & & \\
\hline Monumentos Históricos & $\mathrm{X}$ & & $\mathrm{X}$ & \\
\hline Museu indígena & & $\mathrm{X}$ & $\mathrm{X}$ \\
\hline $\begin{array}{l}\text { Patrimônio Histórico e Artístico } \\
\text { Estadual - Capela Nossa Senhora do } \\
\text { Rosário }\end{array}$ & & & & \\
\hline
\end{tabular}

\footnotetext{
${ }^{7}$ Equipamento (pedaleira) que usa os pés para comandar ações do programa de transcrição, mantendo as mãos livres para a digitação.

${ }^{8}$ Este era o antigo site da prefeitura de Aruanã, correspondente ao domínio http://www.aruana.tur.br, acessado em junho de 2014, e que se encontra atualmente desativado.
} 


\begin{tabular}{|l|l|l|l|l|}
\hline Pista de MotoCross & X & & \\
\hline $\begin{array}{l}\text { Praça Couto Magalhães - Mirante, } \\
\text { pista de caminhada, espaço para } \\
\text { shows eventos. }\end{array}$ & & X & X & \\
\hline $\begin{array}{l}\text { Praça do Bairro Nova Aruanã - Possui } \\
\text { campo de futebol e quadra de } \\
\text { vôlei/futebol de areia, pista de } \\
\text { caminhada e parque infantil }\end{array}$ & & X & \\
\hline $\begin{array}{l}\text { Praça José Pedro Santos - } \\
\text { Equipamentos de Ginástica, pista de } \\
\text { caminhada parque infantil. }\end{array}$ & & X & \\
\hline $\begin{array}{l}\text { Praça Luís Costa Camargo - Possui } \\
\text { campo de futebol, Ginásio } \\
\text { Poliesportivo e campo de } \\
\text { voleibol/futebol de areia, parques } \\
\text { infantis e pista de caminhada. }\end{array}$ & & & \\
\hline Rádio & & & \\
\hline SESI - Aruanã & & & \\
\hline
\end{tabular}

Fonte: Aruanã (2014c).

Dentre as praças da cidade (Figura 02), a maioria conta com equipamentos específicos de lazer voltados para o esporte, com predominância do futebol e do voleibol. Estas se configuram como equipamentos polivalentes de lazer, pois possuem estrutura para esportes como voleibol e futebol, mas permitem programas diversificados, como shows, feiras, dentre outros.

Figura 02 - Praças de Aruanã.

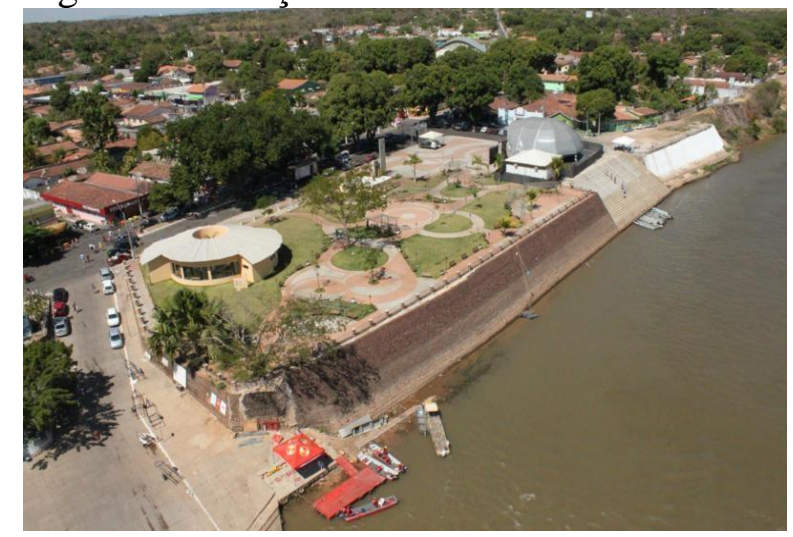

Praça Couto Magalhães.

Fonte: Aruanã (2015a).

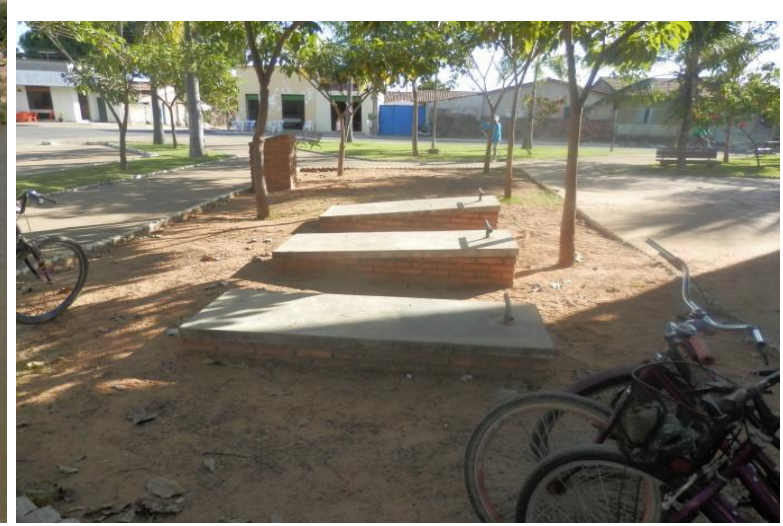

Praça José Pedro Santos.

Fonte: Acervo pessoal. 


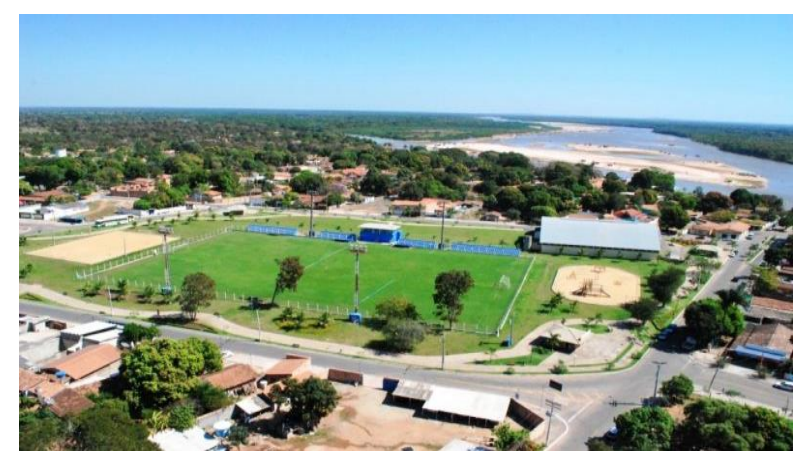

Praça Luís Costa Camargo.

Fonte: Aruanã (2015b).

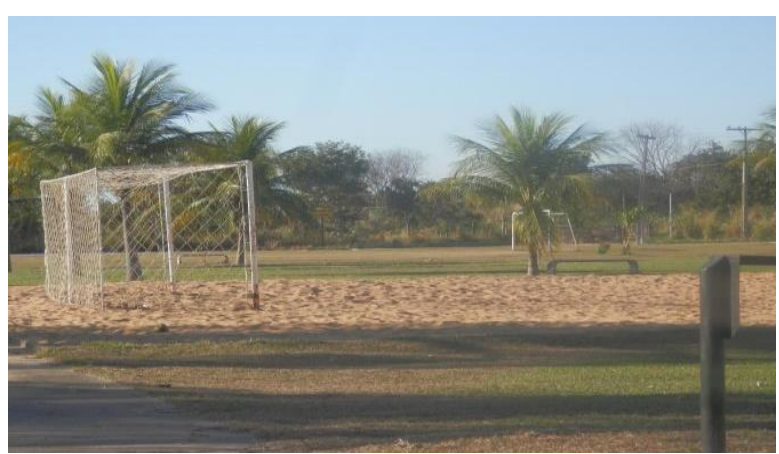

Praça Nova Aruanã.

Fonte: Acervo pessoal.

Observamos um destaque para equipamentos das modalidades voleibol, futebol e futsal nas praças da cidade. Tal característica também foi percebida na fala da Diretoria de Esportes, repetitiva em relação a estas duas últimas ao falar sobre o esporte em Aruanã, semelhante ao apresentado por Carneiro, Moraes e Soares (2014), que investigaram os espaços e equipamentos de esporte e lazer em Uruaçu-GO.

[...] Tem o futsal, o futsal né, masculino e feminino, nós temos um time de futsal feminino também, que representa/recentemente nós estávamos nos jogos abertos na cidade de São Miguel do Araguaia, categoria futsal masculino e feminino, e, o society masculino. [...] (DIRETORIA DE ESPORTES, 2014).

[...] A gente faz os campeonatos na categoria de base, dentro das idades, divide a própria escolinha e libera pra alguns que não participam da escolinha, participar também. Durante o ano também, alguns amistosos entre as escolinhas; por exemplo, no sábado agora tem o sub 11 e o sub 13 vai estar indo para a cidade de Matrinchã fazer um amistoso. [...](DIRETORIA DE ESPORTES, 2014).

A Diretoria de Esportes afirmou que existem iniciativas para promoção de outras modalidades, como o handebol e o basquetebol, mas que ainda não haviam iniciado: "Vamos iniciar agora no mês de agosto o handebol, o basquetebol e o voleibol, pra estar iniciando a iniciativa esportiva também nas escolinhas nessas áreas." (DIRETORIA DE ESPORTES, 2014). ${ }^{9}$

Em relação a outras práticas não esportivas, a Direção de Esportes (2014) nos informou que há no CRAS (Centro de Referência de Assistência Social)

[...] durante o ano, o pessoal da terceira idade trabalha através do CRAS, na piscina, tem um professor de Educação Física que coordena lá [...]. Tem o

\footnotetext{
${ }^{9}$ Em novembro de 2015 nada consta no website oficial da prefeitura de Aruanã sobre a implantação destas modalidades.
} 
trabalho da Capoeira e do Judô também. [...] aula de ginástica e jump. E no mês de julho o jump vem aqui pra praça. ${ }^{10}$

Destas práticas, pudemos observar apenas a ginástica e o jump, pois durante o mês de julho estas acontecem na praça Couto Magalhães, às 18:30h. Percebemos que esta é uma prática organizada, que conta com a presença de um professor de Educação Física, e um grande número de praticantes acompanha a aula (a maioria do sexo feminino), que é gratuita e aberta para turistas e moradores.

Inferimos que discutir o lazer na cidade não pode desconsiderar os eventos realizados que envolvem a demanda turística. Estes aumentam a visibilidade da cidade, gerando mais emprego e renda, mas se trata também do aumento de práticas de lazer para o cidadão, já que parte destes assiste aos shows e apresentações culturais. O Festival Aruanã EmCanto é um exemplo, pois

[...] é um festival destinado à promoção do turismo no Vale do Araguaia, incentivando o fluxo de visitantes e turistas. Tem como plano de fundo abrir importante espaço aos compositores e intérpretes goianos, voltados para os gêneros: sertanejo, MPB e pop/rock. Busca ainda incentivar o interesse da população pela música como fonte de cultura e lazer, fomentando, claro, o turismo. (ARUANÃ EMCANTO, 2014). ${ }^{11}$

Em nossa avaliação, estas ações tem como foco atrair o turista para a região, com aumento das ofertas de emprego e renda para a população. Portanto são políticas públicas que fomentam trabalho para o cidadão aruanense, e não o lazer, mesmo que em alguns casos haja a apropriação destes eventos por parte dos habitantes locais.

Quando questionados sobre as dificuldades da gestão, a resposta foi categórica sobre os recursos financeiros para realização dos projetos:

A primeira grande dificuldade e talvez a dificuldade ${ }^{12}$ : recursos financeiros, [...] não há dinheiro que de conta de tudo, até porque a cada momento que uma cidade cresce e que se transforma, vem mais gente, e consequentemente, surgem novos problemas [...]. Hoje nós estamos carentes de um centro de convenções, e que nós temos certeza que vai valorizar não só Aruanã, mas o Vale do Araguaia em si. (PREFEITURA, 2014).

A viabilidade financeira de uma cidade é um dos fatores que mais influenciam na realização de obras, construções e iniciativas. Neste aspecto a Prefeitura afirma fazer parcerias com a iniciativa privada e conta com o apoio do Governo do Estado de Goiás, mas

\footnotetext{
${ }^{10}$ Não houve detalhamento sobre o número de pessoas que participam destas ações, tampouco sobre o perfil das mesmas.

11 Estas informações foram coletadas a partir do site do evento: http://www.aruanaemcanto.com.br/o-festival-

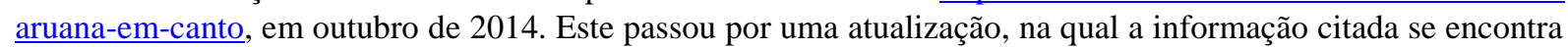
indisponível.

$12 \mathrm{O}$ grifo foi dado pela entonação do respondente ao dizer estas palavras.
} 
ressalta as dificuldades de angariar fundos do Governo Federal, por questões burocráticas. Na fala da Prefeitura (2014):

Hoje eu falo que pra esses grandes eventos eu tenho tido $90 \%$ do apoio do Governo do Estado, e pouquíssimas ações do Governo Federal e eu explico o por quê. A questão documental, a movimentação documental dentro do Ministério do Turismo em nível federal, ela dificulta muito [...].

Estes dados confirmam as assertivas de Amaral (2004), já que pouco capital disponível gera uma disputa de poder no que diz respeito a qual setor este será investido, ou mesmo em quais setores se torna necessário buscar novos recursos em esferas estaduais e federais. Conforme apontado por Silva et al (2011) estas relações são mediadas pela política, e são nas políticas públicas que aparecem as ações de manutenção ou mudança de cenários.

Um exemplo desta relação na cidade de Aruanã está na proibição de festas com som automotivo na cidade. Na visita de campo realizada em 2013, ao redor da Igreja Nossa Senhora do Rosário ${ }^{13}$, durante a noite, aconteciam festas com o uso de diversos automóveis com aparelhos de som potentes, com autorização da prefeitura. Ao voltarmos à cidade no ano de 2014, em nossas conversas com a Gestão Municipal, esta informou que o som automotivo foi proibido. A demanda da população e dos turistas, fez com que a cidade procurasse novas formas de se organizar para manter seu público alvo, o 'turista família'.

Um ganho que a gente teve muito grande foi proibir o som automotivo. Por que até o ano passado nós tínhamos, então as pessoas foram percebendo, é questão de mudança [...]. No final do ano passado a gente já teve um evento, no aniversário da cidade, sem som automotivo, no carnaval que foi a grande prova, a gente fez um evento sem som automotivo, e eles começaram a perceber que, que realmente o público, o perfil de público, que família é muito mais rentável, muito mais fácil de trabalhar, as possibilidades são maiores, com esse público, então assim, a gente ganhou bastante com isso também (SECRETARIA DE TURISMO, 2014).

A presença do som automotivo na cidade e, depois, sua ausência determinada pela administração local, nos mostra o que Mascarenhas (2003) denomina de "pedaço sitiado". Mas importa observar que, apesar de indicar um 'ganho' com a proibição, a administração da cidade destaca que, na sua implantação, o programa de som automotivo cumpriu importante papel num momento em que a cidade passava por dificuldades para atrair os turistas:

Eu queria abrir um parênteses para que as pessoas entendam o que ocorreu. Aruanã chegou num ponto, há mais ou menos 10 anos atrás, que não tinha datas comemorativas, não tinha aniversário, não tinha réveillon, não tinha temporada, não tinha festa religiosa, não tinha nada. E foi necessário

13 Esta igreja é um Patrimônio Histórico, tombada do pelo Governo do Estado de Goiás, e na época das duas visitas de campo, passava por reforma, portanto não tivemos acesso ao seu interior. Mas esta é uma opção de lazer tanto para os turistas, quanto para os moradores da cidade, no que diz respeito ao seu aspecto histórico e patrimonial. 
desenvolver um trabalho, assim que o ex-prefeito H.C assumiu, pra trazer o turista de volta para Aruanã. Mas a cidade não tinha recurso, e ele viu naquela ocasião o som automotivo como uma oportunidade, como uma chance de fazer com que famílias, jovens, viessem para Aruanã, e naquele momento foi positivo e foi uma atração. (PREFEITURA, 2014).

Esta perspectiva mostra claramente a relação entre as ofensivas da globalização (o som automotivo) em um local onde a cultura tradicional ainda é presente. $\mathrm{O}$ respaldo e aprovação da população mediante esta decisão indicam possibilidades de enfrentamento e participação política no que diz respeito às relações de poder (AMARAL, 2004), e mostra as 'contrarracionalidades' defendidas por Mascarenhas (2003, p.139 - 140), em que a população se apropria de valores e significados para se opor a tais avanços, em uma demonstração de democracia e força popular.

\section{Considerações Finais}

Pudemos perceber que as políticas públicas de lazer e esporte da cidade de Aruanã são influenciadas em grande parte pela demanda turística, principalmente no que diz respeito às ações voltadas ao lazer fora do conteúdo esportivo. Este por sua vez tem como ênfase o futebol e o futsal, tanto nas ações quanto nos espaços e equipamentos de lazer.

Observamos que em vários momentos a Gestão Municipal tem se preocupado em atender as demandas da população em manobras que também captam recursos para o turismo, como é o caso dos eventos gratuitos promovidos. Esta inclusive é uma característica interessante da cidade, pois ao mesmo tempo em que um evento se mostra - por um lado, como trabalho para boa parcela da cidade, por outro lado se apresenta como oportunidade para o lazer, ainda que este não seja o foco destas ações que, conforme apontamos, se configuram como ações voltadas para o trabalho.

Reconhecemos que a pesquisa se limitou ao ponto de vista dos Gestores e da observação dos espaços públicos, deixando uma lacuna no que diz respeito à própria população em relação às políticas públicas de esporte e lazer. Isto se constituiu como elemento limitador de nossas análises, indicando a necessidade futura de ampliação do estudo para outros sujeitos, buscando uma compreensão mais próxima da realidade.

Consideramos que esta pesquisa é um avanço na produção acadêmica por revelar especificidades de um fenômeno social característico do Estado de Goiás, que é o turismo no rio Araguaia, com indicações sobre a peculiaridade da cidade de Aruanã, o que permitiu um contato com a realidade de uma cidade pequena, mas que exerce um papel sócio-histórico, econômico e cultural significativo neste Estado. A busca pela compreensão das políticas públicas de lazer e esporte traz uma reflexão sobre um contexto da realidade local, e esperamos que sirva para o crescimento do debate acerca do lazer, do esporte e das políticas públicas em Goiás.

Por fim, fica a observação indignada de que a população brasileira, marcadamente aquela presente em pequenos municípios, está à mercê de políticas públicas de esporte e lazer restritivas, afuniladas hegemonicamente para o futebol, respondendo aos interesses de parcelas pouco significativas de tais populações, detentoras dos poderes decisórios e de encaminhamentos, num processo dissonante com a democracia e seus princípios. 


\title{
PUBLIC POLICIES FOR LEISURE AND SPORT IN THE CITY OF ARUANÃ - GO.
}

\begin{abstract}
This research aimed to investigate the public policies for leisure and sport in the city of Aruanã - GO, destined for its residents. The instruments for data collection were a semi structured interview (adapted from INÁCIO, 2007) with representatives of Municipal Management, a systematic observation and recording of images of spaces and equipments of leisure and sport. The results indicate the sport as the predominant content of the leisure in public policies as well as soccer as hegemonic modality, and that the actions directed to the inhabitants are low when compared to actions to tourists. We conclude that leisure citizen is in a position of disadvantage compared to public policies aimed at the tourist demand.
\end{abstract}

Keywords: Public policies; Leisure; Sport; Aruanã.

\section{POLÍTICAS PÚBLICAS PARA EL OCIO Y DEPORTE EN LA CIUDAD DE ARUANÃ - GO}

\begin{abstract}
Resumen
Esta investigación identificó las políticas públicas para el deporte/ocio en la ciudad de Aruanã/Brasil. Para tanto utilizó la entrevista semi-estructurada con la Administración Municipal; observación sistemática de los espacios de ocio/deporte y grabación de imágenes de los espacios y equipamientos. Los resultados indican predominio del deporte como ocio y el fútbol como práctica hegemónica, y que las acciones de la administración para los ciudadanos aruanenses son frágiles. Se concluye que el ocio de los ciudadanos está en desventaja respecto a las políticas públicas orientadas al turismo, lo que genera un hecho típico de las regiones turísticas: la utilización de los recursos públicos con el turista mientras el ciudadano local está situado en la orilla.
\end{abstract}

Palabras claves: Políticas públicas; Ocio; Deporte; Aruanã.

\section{Referências}

ADORNO, T.; HOERKHEIMER, M. A indústria cultural: $\mathrm{O}$ esclarecimento como mistificação das massas. In ADORNO, T.; HOERKHEIMER, M. Dialética do Esclarecimento: fragmentos filosóficos. 1947.p.57-79. Disponível em < http://charlezine .com.br/wp-content/uploads/Dial\%C3\%A9tica-do-Esclarecimento-Adorno.pdf $>$. Acesso em 12 nov. 2015.

AMARAL, S. C. F. Políticas Públicas. In GOMES, C. L.(org). Dicionário Crítico do Lazer. Belo Horizonte: Autêntica, 2004. p. 181-185.

ÂNGElO, P. G.; CARVALHO, A. R. Valor recreativo do rio Araguaia, região de Aruanã, estimado pelo método do custo de viagem. Acta Scientiarum. Biological Sciences. Maringá. v. 29, n. 4, p. 421-428, 2007. Disponível em < http://periodicos.uem.br/ojs/index.php/Acta SciBiolSci/article/view/886/432>. Acesso em 12 nov. 2015.

ARUANÃ EMCANTO. Site do evento. Disponível em < http://www.aruanaemcanto.com.br 
/o-festival-aruana-em-canto/> Acesso em 12 nov. 2015.

ARUANÃ. Site oficial da prefeitura de Aruanã. 2015a. Disponível em <http://www.aruana.go.gov.br/img/galeria/g/87796a672bfe9d867066d145fc234538.jpg>.

Acesso em 12 nov. 2015.

ARUANÃ. Perfil Facebook da Prefeitura Municipal de Aruanã. 2015b. Disponível em <https://www.facebook.com/Prefeitura-Municipal-de-Aruan\%C3\%A3-201885343301694 /photos_stream>. Acesso em 12 nov. 2015.

AZEVEDO, C. E. F. et al. A estratégia da triangulação: Objetivos, possibilidades, limitações e proximidades com o pragmatismo. In Encontro de Ensino e Pesquisa em Administração e Contabilidade, 4, 2013, Brasília. Anais do IV Encontro de Ensino e Pesquisa em Administração e Contabilidade. 2013, Brasília. Disponível em <http://www.anpad.org .br/diversos/trabalhos/EnEPQ/enepq_2013/2013_EnEPQ5.pdf>. Acesso em 12 nov. 2015.

BRACHT, V. Sociologia crítica do esporte: uma introdução. 3. ed. Ijuí: Editora Unijuí, 2005.

CARNEIRO, F. H. S.; MORAES, F. M. S.; SOARES, L. F. R. Espaços e equipamentos públicos de esporte e lazer .em Uruaçu-GO: Políticas públicas e apropriação. In: CONGRESSO CENTRO OESTE DE CIÊNCIAS DO ESPORTE, 6. CONGRESSO DE EDUCAÇÃO FÍSICA, 10, 2014, Jataí. Anais Eletrônicos do VI CONCOCE e X CONEF, Jataí, 2014 GTT Políticas Públicas. Disponível em < http://congressos.cbce.org.br/index.php/ 6concoce/10conef/paper/view/6214>. Acesso em 12 nov. 2015.

CHIZZOTTI, A. Da pesquisa qualitativa. In: CHIZZOTTI, A. Pesquisas em ciências humanas e sociais. 3. ed. São Paulo: Cortez, 1998. P. 77-87.

FREIRE, D. R. A.; ROCHA JUNIOR, C. P. Lazer e Políticas Públicas na Bahia: Interpretações de um Modelo. Licere, Belo Horizonte, v. 18, p. 96-113, jun.2015. Disponível em < https://seer.lcc.ufmg.br/index.php/licere/article/view/1046/755>. Acesso em 12 nov. 2015 .

GOMES, R. et al. Organização, processamento, análise e interpretação de dados: o desafio da triangulação. In: MINAYO, M. C. S.; ASSIS, S. G.; SOUZA, E. R. Avaliação por triangulação de métodos: a abordagem de programas sociais. Rio de janeiro: Editora Friocruz, 2005. p. 185-221.

IBGE. Cidades@. Disponível em <http://www.cidades.ibge.gov.br/xtras/perfil.php?lang $=\&$ codmun $=520250 \&$ search $=\|$ infogr\%E1ficos:-informa\%E7\%F5es-completas $>$. Acesso em Acesso em 12 nov. 2015.

INÁCIO, H. L. D. O Ecoturismo como vetor de desenvolvimento territorial sustentável. 2007. 240f. Tese (Doutorado em Sociologia Política) - Programa de Pós-Graduação em Sociologia Política, Centro de Filosofia e Ciências Humanas, UFSC, Santa Catarina 2007. 
Disponível em < https://repositorio.ufsc.br/bitstream/handle/123456789/103186/248836.pdf ?sequence=1\&isAllowed=y $>$. Acesso em 07 dez. 2015.

INÁCIO, H. L. D. O lazer do trabalhador em um contexto de transformações tecnológicas. 1997. 111f. Dissertação (Mestrado em Educação) - Programa de Pós-Graduação em Educação, Centro de Ciências da Educação, UFSC, Florianópolis, 1997. Disponível em $\langle$ https://repositorio.ufsc.br/bitstream/handle/123456789/77154/248937.pdf?sequence=1 > Acesso em 12 nov. 2015.

MARCONI, M. A.; LAKATOS, E. M. Fundamentos de metodologia científica. 3. ed. São Paulo: Atlas, 1991.

MASCARENHAS, F. "Lazerania" também é conquista: tendências e desafios na era do mercado. Movimento, Porto Alegre, v.10, n. 2, p. 73-90, mai./ago., 2004 . Disponível em < http://seer.ufrgs.br/Movimento/article/download/2841/1454>. Acesso em 12 nov. 2015.

MASCARENHAS, F. O pedaço sitiado: cidade, cultura e lazer em tempos de globalização. Revista Brasileira de Ciências do Esporte. Campinas (SP). v. 24, n. 3, p. 121-143, maio 2003. Disponível em <http://oldarchive.rbceonline.org.br/index.php/RBCE/article/view/ $\underline{767 / 441>}$. Acesso em 12 nov. 2015.

MUNICÍPIOS GOIANOS. Blog dedicado a descrever e apresentar os perfis e os fatos históricos e interessantes de todos os 246 municípios do belíssimo estado de Goiás. Disponível em < http://upload.wikimedia.org/wikipedia/commons/thumb/b/b2/Goias _Municip_Aruana.svg/624px-Goias_Municip_Aruana.svg.png>. Acesso em 12 nov. 2015.

NEGRINE, A. Instrumentos de coleta de informações na pesquisa qualitativa. In: TRIVIÑOS, A. N. S.; NETO, V. M. (Orgs.) A pesquisa qualitativa na educação física: alternativas metodológicas. Porto Alegre: Ed. Universidade/UFRGS/Sulina, 1999. p.61-93.

RECHIA, S. Espaço e planejamento urbano na sociedade contemporânea: políticas públicas e a busca por uma marca indenitária de Curitiba. Movimento, Porto Alegre,v.11,n.3, p.49-66, set./dez., 2005. Disponível em: <http://www.seer.ufrgs.br/Movimento/article/download/2882 11496>. Acesso em 12 nov. 2015.

SILVA, D. A. M. et al. Gestão de Políticas Públicas de Esporte e Lazer: Princípios e Pressupostos Teóricos. Brasília: Ideal, 2011.

STAREPRAVO, F. A. Políticas Públicas de Esporte e Lazer no Brasil: Aproximações, intersecções, rupturas e distanciamentos entre os Subcampos Político/Burocrático e Científico/Acadêmico. 2011. 421f. Tese (Doutorado em Educação Física), Departamento de Educação Física, Setor de Ciências Biológicas da UFPR, Curitiba, 2011. Disponível em: $<$ http://www.pgedf.ufpr.br/downloads/TESES/2011/Tese $\% 20$ Fernando\%20Augusto $\% 20 \mathrm{St}$ arepravo.pdf $>$

STIGGER, M. P. Esporte, Lazer e Estilos de Vida: um estudo etnográfico. Campinas: 
Autores Associados, 2002.

STUCCHI, S. Espaços e equipamentos de recreação e lazer. In BRUHNS, H. T. (org.) Introdução aos estudos do lazer. Campinas, SP: Editora da UNICAMP, 1997. p. 105-122.

Recebido em: 13/11/2015

Revisado em: 28/11/2015

Aprovado em: 13/12/2015

Endereço para correspondência:

oromar.augusto@gmail.com

Oromar Augusto dos Santos Nascimento

Universidade de Brasília, Faculdade de Educação Física.

Campus Universitário Darcy Ribeiro

Asa Norte

70910-970 - Brasília, DF - Brasil 